\title{
IDENTYFIKACJA WSPÓŁCZYNNIKA WNIKANIA CIEPŁA NA ZEWNETRZNEJ POWIERZCHNI TERMOMETRU DO WYZNACZANIA NIEUSTALONEJ TEMPERATURY PŁYNU
}

\begin{abstract}
Opracowano metodę wyznaczania współczynnika wnikania ciepła na powierzchni zewnętrznej termometru służącego do pomiaru temperatury czynnika przepływającego pod wysokim ciśnieniem. Metoda opiera się na rozwiązaniu odwrotnego zagadnienia przewodzenia ciepła. Współczynnik wnikania ciepła jest określany na podstawie pomiaru temperatury w środku metalowego cylindrycznego termometru oraz na podstawie pomiaru temperatury ścianki cylindrycznego rurociągu, który jest izolowany cieplnie. Dodatkowo jest wyznaczany współczynnik wnikania ciepła na wewnętrznej powierzchni rurociągu. Korelacje na liczby Nusselta, z których są wyznaczane współczynniki wnikania ciepła na zewnętrznej powierzchni termometru i wewnętrznej powierzchni rurociągu, zawierają nieznane współczynniki, które wyznacza się metodą najmniejszych kwadratów. Wyznaczone współczynniki wykazują dobrą zgodność ze współczynnikami przyjętymi podczas rozwiązywania zagadnienia bezpośredniego.
\end{abstract}

Słowa kluczowe: pomiar temperatury płynu, stan nieustalony, odwrotne zagadnienie przewodzenia ciepła, metoda krocząca, korelacja na liczbę Nusselta

\section{Wstęp}

Do dokładnego wyznaczenia nieustalonej temperatury czynnika niezbędna jest identyfikacja współczynnika wnikania ciepła na zewnętrznej powierzchni termometru o nowej konstrukcji. Zastosowanie metody zostanie zilustrowane na przykładzie wyznaczania temperatury pary nasyconej przepływającej w rurociągu o promieniu powierzchni zewnętrznej $0,1775 \mathrm{~m}$ i grubości ścianki $0,05 \mathrm{~m}$. Do obliczeń zostaną przyjęte stałe właściwości fizyczne materiału ścianki rurociągu: iloczyn gęstości i ciepła właściwego $\rho c=3,7665 \cdot 10^{6} \mathrm{~J} /\left(\mathrm{m}^{3} \cdot \mathrm{K}\right)$, współczynnik wyrównywania temperatury (dyfuzyjność cieplna) $a=7,699 \cdot 10^{-6} \mathrm{~m}^{2} / \mathrm{s}$. Temperatura ścianki rurociągu będzie mierzona na powierzchni zewnętrznej. Wewnątrz

\footnotetext{
${ }^{1}$ Autor do korespondencji/corresponding author: Jan Taler, Politechnika Krakowska, al. Jana Pawła II 37, 31-864 Kraków, tel.: (12) 6283554, e-mail:taler@mech.pk.edu.pl.

${ }^{2}$ Magdalena Jaremkiewicz, Politechnika Krakowska, e-mail: mjaremkiewicz@pk.edu.pl.
} 
rurociągu zostanie umieszczony cylinder stalowy o promieniu powierzchni zewnętrznej $0,0035 \mathrm{~mm} \mathrm{z}$ otworem, w środku którego znajduje się cienki termoelement. Właściwości fizyczne elementu cylindrycznego są następujące: $\rho c=$ $=3,6751 \cdot 10^{6} \mathrm{~J} /\left(\mathrm{m}^{3} \cdot \mathrm{K}\right), a=1,317 \cdot 10^{-5} \mathrm{~m}^{2} / \mathrm{s}$. Najpierw będą wygenerowane dane pomiarowe „dokładne”, przez rozwiązanie zagadnienia bezpośredniego, a następnie wyznaczone poszukiwane współczynniki w korelacjach na liczbę Nusselta.

\section{Matematyczne sformułowanie problemu}

Temperatura przepływającego czynnika będzie wyznaczana na podstawie pomiaru temperatury $\mathrm{w}$ osi cylindra (termometru) oraz pomiaru temperatury ścianki (rys. 1.).

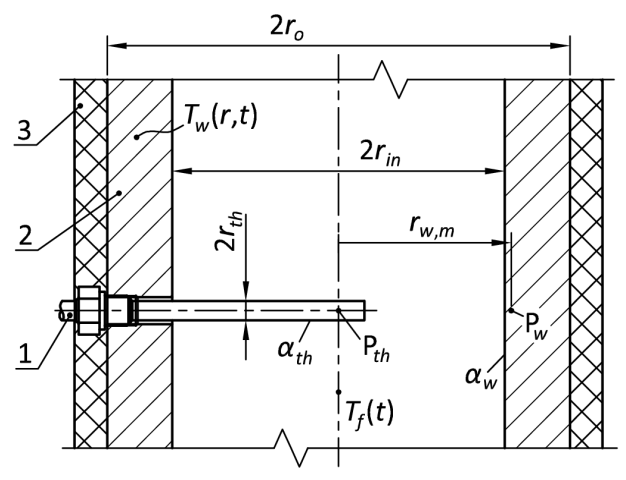

Rys. 1. Pomiar temperatury czynnika w rurociągu; 1 - cylindryczny termometr, 2 - rurociąg, 3 - izolacja rurociągu, $P_{t h}-$ punkt pomiaru temperatury termometru usytuowany w jego osi, $P_{w}$ - punkt pomiaru temperatury wewnątrz ścianki rurociągu

Fig. 1. Measurement of the temperature of the medium in the pipeline; 1 - cylindrical thermometer, 2 - pipeline, 3 - insulation of the pipeline, $P_{t h}$ - temperature measurement point located at the axis of the thermometer, $P_{w}$ - temperature measurement point inside the pipeline wall

Pole temperatury w cylindrycznym termometrze jest opisane równaniem nieustalonego przewodzenia ciepła:

$$
c_{t h}\left(T_{t h}\right) \rho_{t h}\left(T_{t h}\right) \frac{\partial T_{t h}}{\partial t}=\frac{1}{r} \frac{\partial}{\partial r}\left[r \lambda_{t h}\left(T_{t h}\right) \frac{\partial T_{t h}}{\partial r}\right], \quad 0 \leq r \leq r_{t h}
$$

oraz warunkami brzegowymi:

$$
\begin{aligned}
& \left.\frac{\partial T_{t h}}{\partial r}\right|_{r=0}=0 \\
& \left.T_{t h}\right|_{r=0}=f_{t h}(t)
\end{aligned}
$$

zadanymi w środku cylindra dla $r=0$. Jest to odwrotne zagadnienie przewodzenia ciepła, gdyż dla $r=0$ znana jest temperatura i gęstość strumienia ciepła, a temperatura zewnętrznej powierzchni termometru nie jest znana. 
We wzorach (1)-(3) przyjęto następujące oznaczenia: $c_{t h}, \rho_{t h}, \lambda_{t h}-$ odpowiednio ciepło właściwe, gęstość i współczynnik przewodzenia ciepła materiału termometru, $f_{t h}$ - temperatura mierzona w środku termometru, $r$ - promień, $r_{t h}$ - promień powierzchni zewnętrznej termometru, $t$-czas, $T_{t h}$ - temperatura termometru.

Nieustalony rozkład temperatury w ściance rurociągu wyznacza się z równania przewodzenia ciepła:

$$
c_{w}\left(T_{w}\right) \rho_{w}\left(T_{w}\right) \frac{\partial T_{w}}{\partial t}=\frac{1}{r} \frac{\partial}{\partial r}\left[r \lambda_{w}\left(T_{w}\right) \frac{\partial T_{w}}{\partial r}\right], \quad r_{i n} \leq r \leq r_{o}
$$

oraz warunków brzegowych:

$$
\begin{aligned}
& {\left.\left[\lambda_{w}\left(T_{w}\right) \frac{\partial T_{w}}{\partial r}\right]\right|_{r=r_{o}}=0} \\
& \left.T_{w}\right|_{r=r_{w m}}=f_{w}(t)
\end{aligned}
$$

Gęstość strumienia ciepła na zewnętrznej powierzchni rurociągu jest równa zeru (5) z uwagi na przyjętą doskonałą izolację cieplną. Temperatura ścianki jest mierzona w punkcie $r=r_{w, m}$ leżącym wewnątrz ścianki. W pracy przyjęto, że punkt $P_{w}$ leży na zewnętrznej powierzchni rurociągu i $r_{w, m}=r_{o}$. W warunku brzegowym (6) symbol $f_{w}(t)$ oznacza zmierzony przebieg temperatury. Symbole $r_{i n} \mathrm{i} r_{o}$ oznaczają odpowiednio promienie powierzchni wewnętrznej i zewnętrznej rurociągu. Przy założeniu, że współczynnik wnikania ciepła na zewnętrznej powierzchni termometru $\alpha_{t h}$ jest znany, temperaturę płynu $T_{f, t h}(t)$ można wyznaczyć z warunku brzegowego na zewnętrznej powierzchni termometru:

$$
\left.\lambda_{t h} \frac{\partial T_{t h}}{\partial r}\right|_{r=r_{t h}}=\alpha_{t h}\left(T_{f, t h}-\left.T_{t h}\right|_{r=r_{t h}}\right)
$$

z którego po przekształceniu otrzymuje się:

$$
T_{f, t h}=\left.T_{t h}\right|_{r=r_{t h}}+\left.\frac{\lambda_{t h}}{\alpha_{t h}} \frac{\partial T_{t h}}{\partial r}\right|_{r=r_{t h}}
$$

W podobny sposób można wyznaczyć temperaturę czynnika $T_{f, w} \mathrm{z}$ warunku brzegowego na wewnętrznej powierzchni rurociągu, przy założeniu że współczynnik wnikania ciepła $\alpha_{w}$ jest znany. $\mathrm{Z}$ warunku brzegowego:

$$
\left.\lambda_{w} \frac{\partial T_{w}}{\partial r}\right|_{r=r_{i n}}=\alpha_{w}\left(T_{f, w}-\left.T_{w}\right|_{r=r_{i n}}\right)
$$


wyznacza się temperaturę czynnika $T_{f, w}$ :

$$
T_{f, w}=\left.T_{w}\right|_{r=r_{\text {in }}}+\left.\frac{\lambda_{w}}{\alpha_{w}} \frac{\partial T_{w}}{\partial r}\right|_{r=r_{\text {in }}}
$$

Temperatury czynnika $T_{f, t h}$ i $T_{f, w}$ określone odpowiednio ze wzorów (8) i (10) powinny być sobie równe. Z uwagi na przybliżony charakter rozkładu temperatury wewnątrz termometru oraz ścianki, które są wyznaczane z rozwiązania zagadnień odwrotnych, temperatury te mogą się różnić. Również współczynnik wnikania ciepła $\alpha_{t h}(t)$ na zewnętrznej powierzchni termometru oraz współczynnik wnikania ciepła $\alpha_{w}(t)$ na wewnętrznej powierzchni rurociągu określa się z korelacji znanych w literaturze. Są to zwykle korelacje wyznaczane dla przepływu rozwiniętego hydrodynamicznie i termicznie w warunkach ustalonych. W rzeczywistych rurociągach występują kolana, zawory, przewężenia lub rozszerzenia przekroju, które zmieniają rozkład prędkości i temperatury w przepływającym czynniku i powodują, że wzory znane z literatury nie mogą być bezpośrednio stosowane do wyznaczania współczynników wnikania ciepła.

W celu wyznaczenia temperatury płynu jest przyjmowana postać korelacji na liczbę Nusselta dla termometru i dla rurociągu, przy czym niektóre współczynniki występujące w korelacji na współczynnik wnikania ciepła na powierzchni termometru $x_{1}, \ldots, x_{m 1}$ oraz wybrane współczynniki w korelacji na współczynnik wnikania ciepła na wewnętrznej powierzchni rurociągu $x_{m 1+1}, \ldots$, $x_{m}$ występujące $\mathrm{w}$ tych wzorach są wyznaczane za pomocą metody najmniejszych kwadratów:

$$
S(\mathbf{x})=\sum_{i=1}^{n}\left[T_{f, t h}\left(t_{i}\right)-T_{f, w}\left(t_{i}\right)\right]^{2}
$$

tak aby suma $S$ osiągała minimum. Wektor poszukiwanych współczynników $\mathbf{x}=\left(x_{1}, x_{2}, \ldots, x_{m 1}, x_{m 1+1}, \ldots, x_{m}\right)^{\mathbf{T}}$ zawiera współczynniki występujące w korelacji na liczbę Nusselta zarówno dla termometru, jak i rurociągu. Liczba nieznanych współczynników $m$ musi być mniejsza niż liczba punktów czasowych $n$. Liczba punktów czasowych $t_{i}, i=1, \ldots, n$, w których są wyznaczane temperatury czynnika $T_{f, t h}$ i $T_{f, w}$, powinna być dostatecznie duża, aby wyeliminować wpływ przypadkowych błędów pomiaru temperatury termometru ścianki i rurociągu. Zwykle w sumie $S$ określonej wzorem (11) uwzględnia się kilkadziesiąt punktów czasowych.

Dla opływanego poprzecznie cylindra (termometru) przyjęto korelacje zaproponowane przez Churchilla i Bernsteina [2], ważne dla $\operatorname{Re}_{t h} \operatorname{Pr}>0,2$. W zależności od liczby Reynoldsa korelacje te mają następującą postać:

- $\mathrm{Re}_{t h}>400000$ 


$$
\mathrm{Nu}_{t h}=0,3+\frac{x_{1} \operatorname{Re}_{t h}^{1 / 2} \operatorname{Pr}^{1 / 3}}{\left[1+(0,4 / \operatorname{Pr})^{2 / 3}\right]^{1 / 4}}\left[1+\left(\frac{\operatorname{Re}_{t h}}{282000}\right)^{5 / 8}\right]^{4 / 5}
$$

- $10000<\mathrm{Re}_{t h}<400000$

$$
\mathrm{Nu}_{t h}=0,3+\frac{x_{1} \operatorname{Re}_{t h}^{1 / 2} \operatorname{Pr}^{1 / 3}}{\left[1+(0,4 / \operatorname{Pr})^{2 / 3}\right]^{1 / 4}}\left[1+\left(\frac{\operatorname{Re}_{t h}}{282000}\right)^{1 / 2}\right]
$$

- $\mathrm{Re}_{t h}<10000$

$$
\mathrm{Nu}_{t h}=0,3+\frac{x_{1} \operatorname{Re}_{t h}^{1 / 2} \operatorname{Pr}^{1 / 3}}{\left[1+(0,4 / \operatorname{Pr})^{2 / 3}\right]^{1 / 4}}
$$

Właściwości fizyczne czynnika przyjmuje się dla średniej arytmetycznej temperatur czynnika i powierzchni cylindra. W oryginalnych wzorach Churchilla i Bernsteina współczynnik $x_{1}=0,62$. Przyjęto następującą postać korelacji na współczynnik wnikania ciepła na wewnętrznej powierzchni rurociągu (wzór Dittusa-Boeltera) [2]:

$$
\mathrm{Nu}_{p}=x_{2} \operatorname{Re}_{p}^{4 / 5} \operatorname{Pr}^{n}
$$

gdzie: $0,7 \leq \operatorname{Pr} \leq 160, \operatorname{Re}_{p}>10000$, stosunek średnicy wewnętrznej rurociągu do jego długości $2 r_{i n} / L>10$, natomiast $n=0,4$ dla nagrzewania, a $n=3$ dla chłodzenia. Właściwości termofizyczne są wyznaczone dla średniej wartości temperatury płynu. W oryginalnej korelacji Dittusa-Boeltera $x_{2}$ przyjmuje wartość 0,023 .

\section{Wyznaczanie nieustalonego rozkładu temperatury w termometrze i ściance rurociągu}

Zagadnienie odwrotne (1)-(3) dla termometru oraz zagadnienie dla rurociągu (4)-(6) rozwiązano metodą kroczącą [1]. Podział termometru i ścianki rurociągu na objętości skończone ilustrują odpowiednio rys. 2a i 2b. Kroczenie w przestrzeni rozpoczyna się od punktu pomiaru temperatury, to jest od środka cylindra w przypadku termometru i od zewnętrznej powierzchni w przypadku rurociągu. Kolejne temperatury w węzłach usytuowanych na promieniu termometru są obliczane z następujących wzorów:

$$
T_{t h, 2}=T_{t h, 1}+\frac{1}{2} \frac{\left(\Delta r_{t h}\right)^{2}}{\lambda_{t h, 1}+\lambda_{t h, 2}} c_{t h, 1} \rho_{t h, 1} \frac{\mathrm{d} T_{t h, 1}}{\mathrm{~d} t}
$$




$$
\begin{aligned}
& T_{t h, 3}=T_{t h, 2}-\frac{1}{3} \frac{\lambda_{t h, 1}+\lambda_{t h, 2}}{\lambda_{t h, 3}+\lambda_{t h, 2}}\left(T_{t h, 1}-T_{t h, 2}\right)+\frac{4}{3}\left(\Delta r_{t h}\right)^{2} \frac{c_{t h, 2} \rho_{t h, 2}}{\lambda_{t h, 3}+\lambda_{t h, 2}} \frac{\mathrm{d} T_{t h, 2}}{\mathrm{~d} t} \\
& T_{t h, 4}=T_{t h, 3}-\frac{3}{5} \frac{\lambda_{t h, 2}+\lambda_{t h, 3}}{\lambda_{t h, 4}+\lambda_{t h, 3}}\left(T_{t h, 2}-T_{t h, 3}\right)+\frac{8}{5}\left(\Delta r_{t h}\right)^{2} \frac{c_{t h, 3} \rho_{t h, 3}}{\lambda_{t h, 4}+\lambda_{t h, 3}} \frac{\mathrm{d} T_{t h, 3}}{\mathrm{~d} t}
\end{aligned}
$$

a)

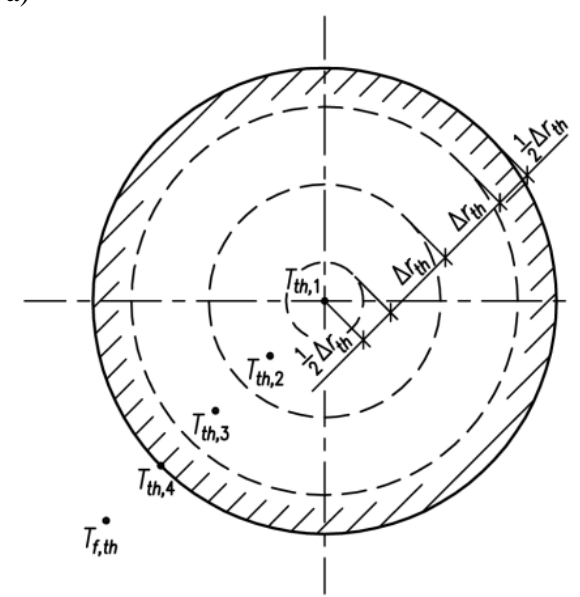

b)

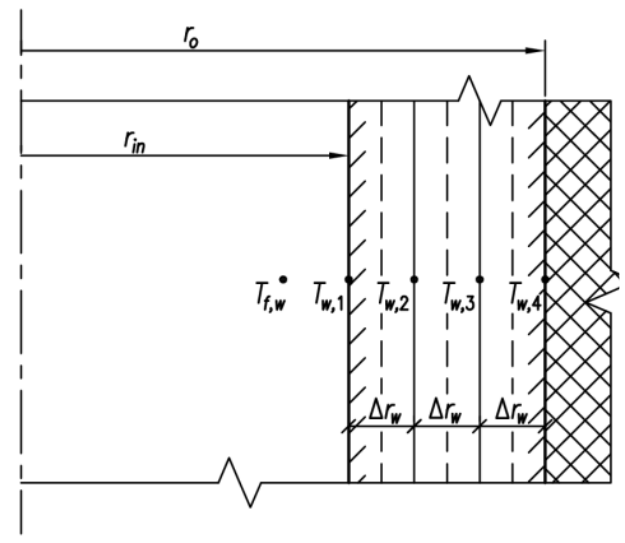

Rys. 2. Podział obszaru na objętości skończone: a) termometr cylindryczny, b) ścianka rurociągu

Fig. 2. Division of the domain into finite volumes: a) cylindrical thermometer, b) pipeline wall nr 4:

Temperaturę czynnika wyznacza się z równania bilansu energii dla węzła

$$
\begin{aligned}
& \pi\left[r_{t h}^{2}-\left(r_{t h}-\frac{\Delta r_{t h}}{2}\right)^{2}\right] c_{t h, 4} \rho_{t h, 4} \frac{\mathrm{d} T_{t h, 4}}{\mathrm{~d} t}= \\
& =2 \pi\left(r_{t h}-\frac{\Delta r_{t h}}{2}\right) \frac{\lambda_{t h, 3}+\lambda_{t h, 4}}{2} \frac{T_{t h, 3}-T_{t h, 4}}{\Delta r_{t h}}+2 \pi r_{t h} \alpha_{t h}\left(T_{f, t h}-T_{t h, 4}\right)
\end{aligned}
$$

z którego po przekształceniu otrzymuje się:

$$
T_{f, t h}=T_{t h, 4}-\frac{5}{12} \frac{\lambda_{t h, 3}+\lambda_{t h, 4}}{\alpha_{t h} \cdot \Delta r_{t h}}\left(T_{t h, 3}-T_{t h, 4}\right)+\frac{11}{24} \Delta r_{t h} \frac{c_{t h, 4} \rho_{t h, 4}}{\alpha_{t h}} \frac{\mathrm{d} T_{t h, 4}}{\mathrm{~d} t}
$$

gdzie: współczynnik przewodzenia ciepła $\lambda_{t h, i}=\lambda_{t h}\left(T_{t h, i}\right), c_{t h, i}=c_{t h}\left(T_{t h, i}\right), \rho_{t h, i}=$ $=\rho_{t h}\left(T_{t h, i}\right)$, a krok przestrzenny w kierunku promieniowym $\Delta r_{t h}=r_{t h} / 3$. 
W podobny sposób wyznacza się temperaturę ścianki oraz temperaturę czynnika. Kroczenie w przestrzeni rozpoczyna się od węzła nr $4 \mathrm{w}$ kierunku powierzchni wewnętrznej. $Z$ równania bilansu energii dla węzła $\mathrm{nr} 4$ wyznaczono temperaturę w węźle $\mathrm{nr} 3$. Następnie są wyznaczane kolejno temperatury w węzłach nr 2 i nr 1. W wyniku takiego postępowania otrzymuje się następujące wyrażenia określające czasowe przebiegi temperatury we wszystkich węzłach:

$$
\begin{aligned}
T_{w, 3}= & T_{w, 4}+\frac{r_{o}^{2}-\left(r_{o}-\Delta r_{w} / 2\right)^{2}}{r_{o}-\Delta r_{w} / 2} \Delta r_{w} \frac{c_{w, 4} \rho_{w, 4}}{\lambda_{w, 3}+\lambda_{w, 4}} \frac{\mathrm{d} T_{w, 4}}{\mathrm{~d} t} \\
T_{w, 2}= & T_{w, 3}+4\left(\Delta r_{w}\right)^{2} \frac{r_{i n}+2 \Delta r_{w}}{2 r_{i n}+3 \Delta r_{w}} \frac{c_{w, 3} \rho_{w, 3}}{\lambda_{w, 2}+\lambda_{w, 3}} \frac{\mathrm{d} T_{w, 2}}{\mathrm{~d} t}- \\
& -\frac{2 r_{i n}+5 \Delta r_{w}}{2 r_{i n}+3 \Delta r_{w}} \frac{\lambda_{w, 3}+\lambda_{w, 4}}{\lambda_{w, 2}+\lambda_{w, 4}}\left(T_{w, 4}-T_{w, 3}\right) \\
T_{w, 1}= & T_{w, 2}+4\left(\Delta r_{w}\right)^{2} \frac{r_{i n}+\Delta r_{w}}{2 r_{i n}+\Delta r_{w}} \frac{c_{w, 2} \rho_{w, 2}}{\lambda_{w, 1}+\lambda_{w, 2}} \frac{\mathrm{d} T_{w, 2}}{\mathrm{~d} t}- \\
& -\frac{2 r_{i n}+3 \Delta r_{w}}{2 r_{i n}+\Delta r_{w}} \frac{\lambda_{w, 2}+\lambda_{w, 3}}{\lambda_{w, 1}+\lambda_{w, 3}}\left(T_{w, 3}-T_{w, 2}\right)
\end{aligned}
$$

$\mathrm{Z}$ równania bilansu energii dla węzła nr 1 :

$$
\begin{aligned}
& \pi\left[\left(r_{i n}+\frac{\Delta r_{w}}{2}\right)^{2}-r_{i n}^{2}\right] c_{w, 1} \rho_{w, 1} \frac{\mathrm{d} T_{w, 1}}{\mathrm{~d} t}= \\
& =2 \pi r_{i n} \dot{q}_{i n}+2 \pi\left(r_{i n}+\frac{\Delta r_{w}}{2}\right) \frac{\lambda_{w, 1}+\lambda_{w, 2}}{2} \frac{T_{w, 2}-T_{w, 1}}{\Delta r_{w}}
\end{aligned}
$$

został wyznaczony strumień $\dot{q}_{i n}$ :

$$
\dot{q}_{i n}=c_{w, 1} \rho_{w, 1} \frac{\Delta r_{w}}{2}\left(1+\frac{\Delta r_{w}}{4 r_{i n}}\right) \frac{\mathrm{d} T_{w, 1}}{\mathrm{~d} t}-\frac{\lambda_{w, 1}+\lambda_{w, 2}}{2} \frac{T_{w, 2}-T_{w, 1}}{\Delta r_{w}}\left(1+\frac{\Delta r_{w}}{2 r_{i n}}\right)
$$

W celu określenia temperatury czynnika przepływającego przez rurę, skorzystano z warunku brzegowego:

$$
\dot{q}_{i n}=\alpha_{w}\left(T_{f, w}-T_{w, 1}\right)
$$


z którego otrzymuje się

$$
T_{f, w}(t)=T_{w, 1}(t)+\frac{\dot{q}_{i n}(t)}{\alpha_{w}}
$$

gdzie gęstość strumienia ciepła na wewnętrznej powierzchni rurociągu $\dot{q}_{i n}$ jest określona wzorem (25).

\section{Przykład zastosowania metody}

Wyznaczone zostaną: temperatura przepływającego czynnika $T_{f}(t)$ oraz współczynnik $x_{2}$ w korelacji (15), przy założeniu, że współczynnik $x_{1}$ we wzorach (12)-(14) wynosi 0,62, zgodnie z propozycją Churchilla i Bernsteina. Promień powierzchni zewnętrznej termometru $r_{t h}=3,5 \mathrm{~mm}=0,0035 \mathrm{~m}$, a wymiary rurociągu są następujące: promień powierzchni zewnętrznej $r_{o}=0,1775 \mathrm{~m}$, grubość ścianki $s=r_{o}-r_{i n}=50 \mathrm{~mm}=0,05 \mathrm{~m}$. Prędkość przepływu pary wodnej

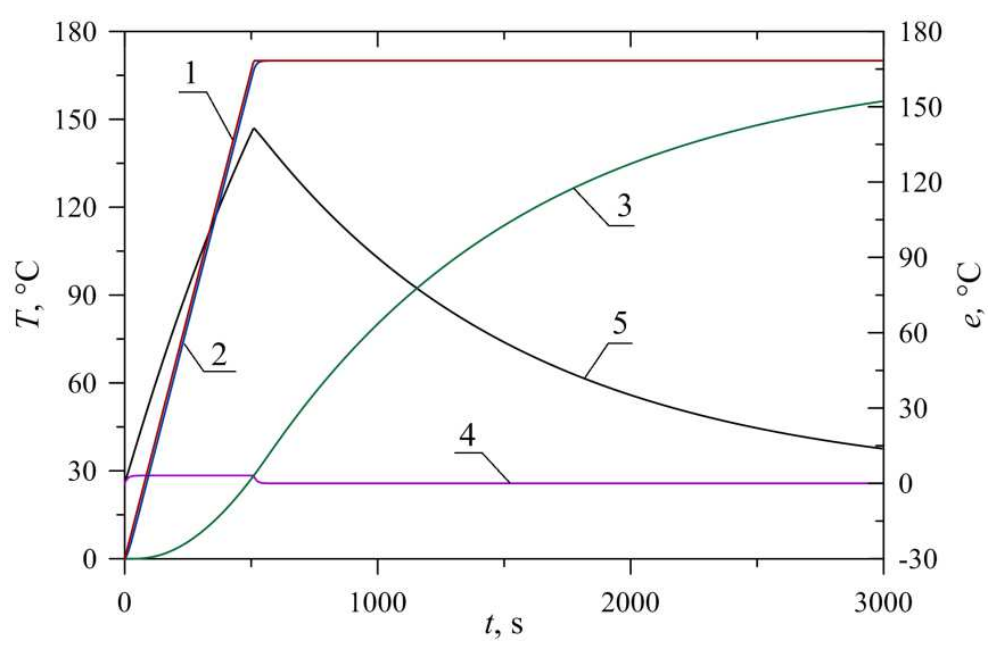

Rys. 3. Temperatura czynnika oraz mierzone temperatury termometru i ścianki rurociągu; 1 - temperatura czynnika $T_{f}, 2$ - temperatura w osi termometru $T_{\text {th }, 1}, 3$ - temperatura zewnętrznej powierzchni rurociągu $T_{w, 1}, 4$ - różnica temperatury między temperaturą czynnika i temperaturą w osi termometru $e_{t h}=T_{f}-T_{t h, 1}, 5$ - różnica temperatury między temperaturą czynnika i temperaturą zewnętrznej powierzchni rurociągu $e_{w}=T_{f}-T_{w, 1}$

Fig. 3. Medium and measured temperatures of the thermometer and pipeline wall temperature; 1 - medium temperature $T_{f}, 2$ - temperature in the axis of thermometer $T_{t h, 1}, 3$ - temperature of pipeline outer surface $T_{w, 1}, 4$ - differrence between the fluid temperature and the temperature at the thermometer axis $e_{t h}=T_{f}-T_{t h, 1}, 5$ - difference between the fluid temperature and the temperature on the outer surface of the pipeline $e_{w}=T_{f}-T_{w, 1}$ 
wynosi $15 \mathrm{~m} / \mathrm{s}$. Przy rozwiązaniu zagadnienia bezpośredniego przyjęto, że temperatura czynnika rośnie ze stałą prędkością $v_{T}=\mathrm{d} T_{f} / \mathrm{d} t=0,3333 \mathrm{~K} / \mathrm{s}$ od temperatury początkowej równej $0^{\circ} \mathrm{C}$ do $170^{\circ} \mathrm{C}$. Po osiągnięciu temperatury $170^{\circ} \mathrm{C}$ temperatura czynnika pozostaje stała. Do obliczeń przyjęto następujące stałe właściwości fizyczne: $c_{t h}=469 \mathrm{~J} /(\mathrm{kg} \cdot \mathrm{K}), \rho_{t h}=7836 \mathrm{~kg} / \mathrm{m}^{3}, \lambda_{t h}=48,4 \mathrm{~W} /(\mathrm{m} \cdot \mathrm{K})$, $c_{w}=486 \mathrm{~J} /(\mathrm{kg} \cdot \mathrm{K}), \rho_{w}=7750 \mathrm{~kg} / \mathrm{m}^{3}, \lambda_{w}=29 \mathrm{~W} /(\mathrm{m} \cdot \mathrm{K})$. Przebieg temperatur zewnętrznej powierzchni termometru i rurociągu, które przyjęto jako zmierzone przebiegi temperatury, przedstawiono na rys. 3 .

Współczynniki wnikania ciepła na powierzchni termometru i rurociągu obliczano za pomocą korelacji (12)-(14) i (15). W sumie kwadratów uwzględniono 200 punktów pomiarowych z krokiem czasowym $5 \mathrm{~s}$. W wyniku przeprowadzonych obliczeń otrzymano stałą $x_{2}=0,0231$. Jest to wartość bardzo bliska stałej $x_{2}=0,023$, występującej we wzorze Dittusa-Boeltera (15). Dla tych samych danych wejściowych przeprowadzono obliczenia, przyjmując $x_{2}=0,023$ i wyznaczając $x_{1}$. W tym przypadku otrzymano wartość $x_{1}=0,638$, która różni się od wartości $x_{1}=0,62$ przyjętej podczas generowania danych pomiarowych. Przyczyną większego błędu wyznaczania $x_{1}$ jest powolna odpowiedź zewnętrznej powierzchni rurociągu na zmiany temperatury czynnika (rys. 3.). W celu poprawnego równoczesnego wyznaczenia stałych $x_{1}$ i $x_{2}$ punkt pomiaru temperatury ścianki powinien być usytuowany w niewielkiej odległości od wewnętrznej powierzchni rurociągu, tak aby tłumienie i opóźnienie sygnału wejściowego, jakim jest temperatura czynnika, nie było zbyt wielkie.

\section{Podsumowanie}

Przedstawiona w artykule metoda może być stosowana podczas wyznaczania nieustalonej temperatury przepływającego czynnika. Temperaturę czynnika można określić z dużą dokładnością dzięki zastosowaniu cylindrycznego termometru, w którego osi jest mierzona jego temperatura. Wykorzystując jako sygnały wejściowe czasowe przebiegi temperatury mierzone w środku termometru i ścianki, wyznacza się temperaturę czynnika za pomocą metody kroczącej, dzięki której można rozwiązać odwrotne zagadnienie przewodzenia ciepła. $\mathrm{Z}$ przeprowadzonych obliczeń testowych wynika, że aby prawidłowo zidentyfikować temperaturę czynnika, promień zewnętrznej powierzchni termometru powinien być tego samego rzędu co odległość punktu pomiaru temperatury ścianki od powierzchni wewnętrznej rurociągu.

\section{Podziękowanie}

Przedstawione $\mathrm{w}$ artykule wyniki zostały uzyskane w badaniach współfinansowanych przez Narodowe Centrum Badań i Rozwoju w ramach umowy PBS1/A4/4/2012 Projekt Badań Stosowanych - Opracowanie nowoczesnych metod oceny trwałości resztkowej elementów ciśnieniowych instalacji energetycznych. 


\title{
Literatura
}

[1] Jaremkiewicz M.: Odwrotne zagadnienia wymiany ciepła występujące w pomiarach nieustalonej temperatury płynów, Wydawn. Politechniki Krakowskiej, Kraków 2012.

[2] Kreith F.: The CRC Handbook of Mechanical Engineering, CRC Press, Inc., Boca Raton, Florida 1998.

\section{IDENTIFICATION OF THE HEAT TRANSFER COEFFICIENT ON THE EXTERNAL SURFACE OF THE THERMOMETER USED FOR DETERMINING TRANSIENT FLUID TEMPERATURE}

\begin{abstract}
S u m m a r y
The aim of the study was to develop a method of determining the heat transfer coefficient on the outer surface of the thermometer with the large diameter casing, which is used for measuring the temperature of the fluid flowing under high pressure. The method is based on solving the inverse heat conduction problems. The heat transfer coefficient is determined based on measuring the temperature in the middle of the solid cylinder and the temperature of the pipeline wall which is thermally insulated. The heat transfer coefficient on the inner surface of the pipeline is calculated using the known correlation for the Nusselt number. The correlation for the Nusselt number contains one unknown coefficient which is determined using the least squares method. Several time points are taken into account in the sum of temperature difference squares. The estimated coefficients are in good agreement with the input values used for the solution of the inverse problem.
\end{abstract}

Keywords: fluid temperature measurement, transient state, inverse heat conduction problem, stepwise method, correlation for Nusselt number

DOI: $10.7862 / \mathrm{rm} .2015 .25$

Otrzymano/received: $14.09 .2014 \mathrm{r}$.

Zaakceptowano/accepted: 20.03.2015 r. 